\title{
On the Academic Responsibility and Social Mission of Chinese Postgraduates
}

\author{
Yang $\operatorname{Jun}^{1} \&$ Xie Min $^{2}$ \\ ${ }^{1}$ Southwest Minorities Educational and Psychological Research Center, Southwest University, Chongqing, \\ China \\ ${ }^{2}$ Kunming Vocational College of Art, Kunming, China \\ Correspondence: Yang Jun, Minorities Educational and Psychological Research Center, Southwest University, \\ No2 Tiansheng Road, Chongqing, China. Tel: 86-138-8884-5234. E-mail: yangjun619@sohu.com
}

Received: June 18, 2014 Accepted: June 21, 2014 Online Published: July 11, 2014

doi:10.5539/ass.v10n15p217 URL: http://dx.doi.org/10.5539/ass.v10n15p217

\begin{abstract}
The progress of Chinese society requires scientific development which is the only path to get rid of pre-modernity dilemma and modernity crisis. Under the circumstance of pre-modernity dilemma and modernity crisis, contemporary postgraduates confront many dilemmas and crises both of education and society. Under the guidance of scientific development, the solution is to realize the academic responsibility of postgraduates by scientifically developing, to accomplish the social mission by promoting academic and social progress with the core value of science and democracy.
\end{abstract}

Keywords: scientific development, pre-modernity, modernity, postgraduates

\section{Scientific Development Is the Only Path to Get Rid of Pre-modernity Dilemma and Modernity Crisis}

Scientific development is the necessity of Chinese social development, because there is duality in Chinese economic and social growing. The serious inadequacy and the initial development of modernity, as well as the contradiction between them, determine to follow the path of "scientific development".

\subsection{Pre-modernity Dilemma}

On the one hand, we've made great progress in modernization and economic development, and we are getting closer to modernization. China's GDP and foreign exchange reserves respectively rank second and first in the world. And per capita national income has reached 3000 dollars... On the other hand, there are more than millions of people are struggling for a living, and smallholder production mode is firmly entrenched in the vast rural areas.... Lack of science and democracy is the superficial cause of economic and social backwardness. While the underlying cause of economic and social backwardness is that the thinking pattern and values are not coordinated with modernity, that is to say, the root cause is traditional Chinese culture peculiarity. Traditional Chinese culture has enormous inertia and diffusion. Although feudal economy and political basis as a whole has disappeared, every Chinese of modern times is still deeply influenced by partial traditional system, values and thinking pattern. The peculiarity of Chinese culture is: harmony between man and nature, analogism, virtue, reconciliation. Different understandings of relationship between man and nature result in different directions of Chinese and western culture. So the basic thinking pattern and values of Chinese culture are decided by the fundamental quality of Chinese culture which is harmony between man and nature. As the famous scholar Liang Shuming said, the essence of Chinese culture is will, reconciliation and moderate. (Liang, 1989, p. 55) Firstly, the harmony between man and nature is with a thinking standpoint of integrating the subjective and the objective. And the contradiction between things and the self is moderated, while in western-style they are in opposition. Therefore, in Chinese culture it is not to solve the problem directly, but to moderate. Thus, analogism derives from the thought of the unity of heaven and man which places more emphasis on intuition than essence, values the integration and neglects analysis, and cares more about deduction than induction. The values of "Nature-man-as-one" pay attention to ethical relation, seeking common ground while preserving differences, as well as being brilliant and way the doctrine of mean. Some western scholars state that Chinese culture is "morality-based culture" which pursues the good, and western culture is "mentality-based culture" which pursues the truth, and it makes sense. So, comparatively Chinese culture neglects individuality, and without 
asking from nature, it is hard to develop democracy and science spontaneously. A lot of foreign advanced systems and theories are "acclimatized", even distorted after being introduced into China, why? Power issue has turned into technique issue, and democratic system has act on behalf of private interest, mainly because behind the system it is lack of appropriate culture which includes thinking mode and values. Both Liang Shuming and Chen Duxiu point out that modernization is just illusion if we do not realize "the last awaking of consciousness". Modernity progress is being shackled by a large amount of existing pre-modernity elements. So, the development of various undertakings including education requires scientific theory as guideline.

\subsection{Modernity Crisis}

The soar away success of modernization in China has inevitably brought increasingly deeper modernity crisis. We have not realized coordinated development between rural and urban areas, economy and society, human and nature, domestic growth and opening up. The gap between the city and countryside is growing wider, and it's difficult for peasants to increase income. The development of economy and society in the middle-west of China isn't making good progress, besides, regional growth isn't in balance. Society progress lags behind economy growth, effective solutions to the problem of education, medical service and housing are still not found. Considerable environment damage threatens people's lives. The level of domestic opening up should be improved, and China needs to go global actively. The fundamental spirits of marketing economy are rationality; science and technology which made individualism, money worship, and utilitarianism to the social dominate value. In a word, this unbalanced state stems from too much stress upon instrumental reason the separation between value reason and instrumental reason proposed by Max Weber. (Weber, 2002,) The division between goal and value of social activity is the essential attribute of modern society. At the same time, goal is above value while the latter serves the former, and modern civilization is created. "Man and nature, in addition to person and person are taken into account by instrumental rationalism, besides, all existence is dismembered by limited utility, and everything is regarded abstractly measurable. Tool reason places constraints on the world. As a result, man is involved into logic based on maximizing interest. The whole world is of instrument and means." (Han, 2007, p. 24) Western thoughts including irrationalism, post-modernism, Existentialism essence of abuse of modern society and severely criticize the disadvantage brought by reason and "the accessories". Despite of existing disadvantages in modern social development, we should make reasonable analysis and decisions and not pursue international trend blindly. We have not done enough to improve our social modernity, that's why we should pay attention to developing modernity, not to criticizing it. The progress of modernity factors will bring a lot of problems and contradictions, and in order to solve modernity crisis, the path of "scientific development" should be followed.

\section{Scientific Development and Academic Responsibility of Postgraduates}

Scientific development is the necessity of Chinese social development, so conforming to the historical trend is the only way for postgraduates to obtain an all-round development. Scientific development requires sticking to the pursuit of comprehensive, coordinated and sustainable development, thus, graduate students of modern times should also achieve an all-round development.

\subsection{The Difficulty and Crisis in Postgraduates' Development}

In reality, many social conditions restrict postgraduates' development in a comprehensive, coordinated and sustainable way. With the accelerating pace of postgraduate enrollment expansion, postgraduates are in harder and harder circumstances for existence and development. Firstly, the number of postgraduates grows by leaps and bounds. As a result, individual graduate student tutors almost become counselors, and opportunities for instructions face to face are not numerous. The number of postgraduate increases too much faster than the amount of graduate supervisor. On the other hand, the tutors employed in a hurry are not perfectly qualified. According to economic principles, the tutors' supply and demand are under serious unbalanced conditions, the former is much less than the latter. And "price" of tutor is liable to increase. It's difficult to increase supply of qualified supervisors because of time-delay, so the only solution is to increase the supply of relatively inferior supervisors, or not to raise supply at all. Objectively, the expansion of postgraduate enrollment is not beneficial to improving quality of postgraduate cultivation. Secondly, unhealthy academic environment, popular academic corruption and fraud are bad for postgraduates. Market economy with powerful attraction has captured academy and education. The links between academic research and money are getting tighter. In the absence of effective regulations, academic corruption is inevitable if the academic colludes with status and money. Without money or professor position, most enthusiastic graduate students only disappear in the waves of corruption. Due to the unique nature of academy, "it is difficult for the public to determine whether the scholars treated the public interest sincerely and fairly" and therefore "only their integrity and honesty can be responsible for their own 
consciousness." (John, 1998, p. 120) In the context of market economy, with the market-oriented reform of academic research chains including higher education, academic publishing institution, academic research is captured by utilitarianism, and becomes corruption field for fame and fortune. In recent years, academic fraud incidents have occurred in Korea, Japan and the United States. Also in China professors at Peking University and Tianjin Foreign Languages College are accused of plagiarism, thus we can see a glimpse and see the whole picture. Thirdly, Social climate is not correct, legacy of corruption, money worship and individualism is very heavy. Everyone's nerves are stimulated by the development of market economy. So many people believe the "spirit of capitalism" which is "to squeeze oil from the cow, and to make money from people". This spirit spread to individual graduate students, and it is shown in the following aspects: survival and learning mainly in search of rich, teacher-student relationship and the relation of companion have changed, even become mutual use, cheating. Thus harmonious and friendly relationships fade away. These three issues are the result and the presence of negative factors rooted in traditional culture and the crisis brought by modernity development.

\subsection{Academic Responsibility of Postgraduates}

Deterioration of the external environment does not mean that we must move towards evil, but there are a variety of internal human development trends, good or evil, and also the internal causes of human development is gradually established through interaction with environment. So graduate students should overcome the adverse effects, and improve their own development. Guided by scientific development, postgraduates' development should adhere to comprehensive, coordinated and sustainable development. Primarily graduate students need to do the followings: firstly, foster self-learning ability, and communicate with supervisors positively. In the face of adverse environment, individuals tend to be powerless. Postgraduates should firstly change themselves. The most important success of the traditional Chinese academy education is self-study and comparing notes. The mode which focuses on self-learning, organizing academic exchanges between students and additional instruction from tutors probably is the best choice currently. Secondly, set an example to eliminate academic corruption, uphold academic ecology. As a new generation as well as the main force of academic studies, graduate students have the responsibility and obligation to correct bad practice. The Ministry of Education has promulgated regulations to fight against academic corruption. The state should establish a more rigorous academic supervision system to combat academic corruption, in order to maintain a good academic environment. Thirdly, enhance individual cultivation, and attach less importance to fame and fortune. People become tools, the purpose replaces the value, and everything seems perfect, except the people "disappeared". What students can do is to strengthen self-discipline, to purify the mind, such as Zhu Xi said, "let there be justice but no lust." Spirit being purified, the ideal of life and the academic pursuit will embark on the right path naturally. In short, the scientific development is the guiding light to get rid of pre-modernity plight, is good medicine to eliminate the crisis of modernity.

\section{Science Development and Postgraduates' Social Mission}

Graduate students as social elites, as inquirers of truth, have inevitable social responsibilities. Chinese social problems rooted in modernization and the underdevelopment of modernization, as well as mutual contradiction between them. Many root causes of the educational problem also lie in education modernization and underdevelopment educational modernization and conflicts between them. On the one hand, the decay factor of traditional culture still has a strong inertia and continuity, science and democracy still have not been developed. On the other hand, overflowing tool reason causes alienation of people and education. The essence of scientific development is to stick to science, which means to treat and promote development with the scientific understanding, spirits and methods. Scientific development centers on "science" and "development", points out the solution of pre-modernity dilemma and modernity crisis. And conforming to the trend of the times, scientific development emphasize the development of modernity, namely to focus on solving the problem of pre-modernity dilemma. Therefore, the main task and mission of the current graduate students are: firstly, students should have no superstition on supervisors, or on books, should merely believe the truth during academic research. The essential difference between Chinese and Western culture lies in ways of thinking and values, which is the original cause of the lagging-behind of modernization. Chinese cultural unites subject and object, seeks the good without the truth, emphasizes on group without the individual, and focuses on whole thinking and intuitive thinking, not analysis thinking. In brief, the Chinese scholars are generally lack of rational thinking, and it is hard to develop science spontaneously. Needham mystery is lack of progress. Thus to do research merely for research sake, and to develop rational thinking is fundamental way to promote the development of China's academic development. Secondly, postgraduates' responsibility is to cure society of various evils, and to improve development of science and democracy. Due to the lack of rationality, seeking the good without truth, then science can not develop. For taking group seriously and individual lightly, democracy 
cannot develop. Science and democracy are the two pillars of modern society; education serves for initiation of science and democracy. The essence of science development is to adhere to science, and the core is to stick to the people-oriented. Scientificalization and humanism trend exist in current academic community, but in academic community, especially in social science circles, Scientificalization often suffers criticism and misunderstanding. In China democracy can easily cause misunderstandings, and it is often considered as bourgeois liberalization. Chinese people do not value science and democracy, China education is quite doleful. Our task now is not to criticize modernity in conformity with Westerners, on contrary; we should praise modernity- science, democracy. The mission of academic research is to study how to develop science and democracy, and how to cultivate scientific spirit, scientific awareness, and scientific literacy; how to improve students' spirit of democracy, democratic consciousness and democratic literacy. Graduate students on the one hand should develop academic research scientifically, and develop their democratic quality; on the other hand, in the form of academic research or educational practice, students should develop people's science and democracy, so that science and democracy become people's way of life.

In short, the problems of China's social development and postgraduate education stems from lack of rationality, sometimes mixed with overflowing instrumental rationality. Conversion of thinking way from "the unity of human and nature" to "the division of human and nature" is possible and necessary. The main task of contemporary graduate students is to convert the thinking mode and values, to gain academic rationality, to develop science and democracy, and to serve the needs of socialist (Lei, 2007, pp. 244-252) modernization. Graduate students should not only get their own scientific development, but also should promote the scientific development of the people and society to realize the value of life.

\section{References}

Liang, S. M. (1989). Culture and philosophy of the east and the west. Shanghai: Shanghai book store.

Weber, M. (2002). Protestantism and The Spirit of capitalism. Xian: Shanxi normal university press.

Han, Q. H. (2007). Modern turnaround of Western Philosophy. Changchun: Jilin people's Publishing House.

Brubeck, J. S. (1998). The philosophy of Higher Education. Hangzhou: Zhejiang Education Publishing House.

Lei, X. Y. (2007). Changes in higher education system of China. Wuhan: Huazhong University of Science and Technology press.

\section{Copyrights}

Copyright for this article is retained by the author(s), with first publication rights granted to the journal.

This is an open-access article distributed under the terms and conditions of the Creative Commons Attribution license (http://creativecommons.org/licenses/by/3.0/). 